RAINBOW Vol. 9(2) 2020
UNournal of Literature, Linguistics and
Cultural Studies
https://journal.unnes.ac.id/sju/index.php/rainbow

\title{
The River Exists, Therefore I Am: Ecocriticism, Nature and Human Nature in Willa Cather's The Enchanted Bluff
}

\author{
Alireza Sardari $* \bowtie$ \\ * English Department, Payame Noor University, Tehran, Iran
}

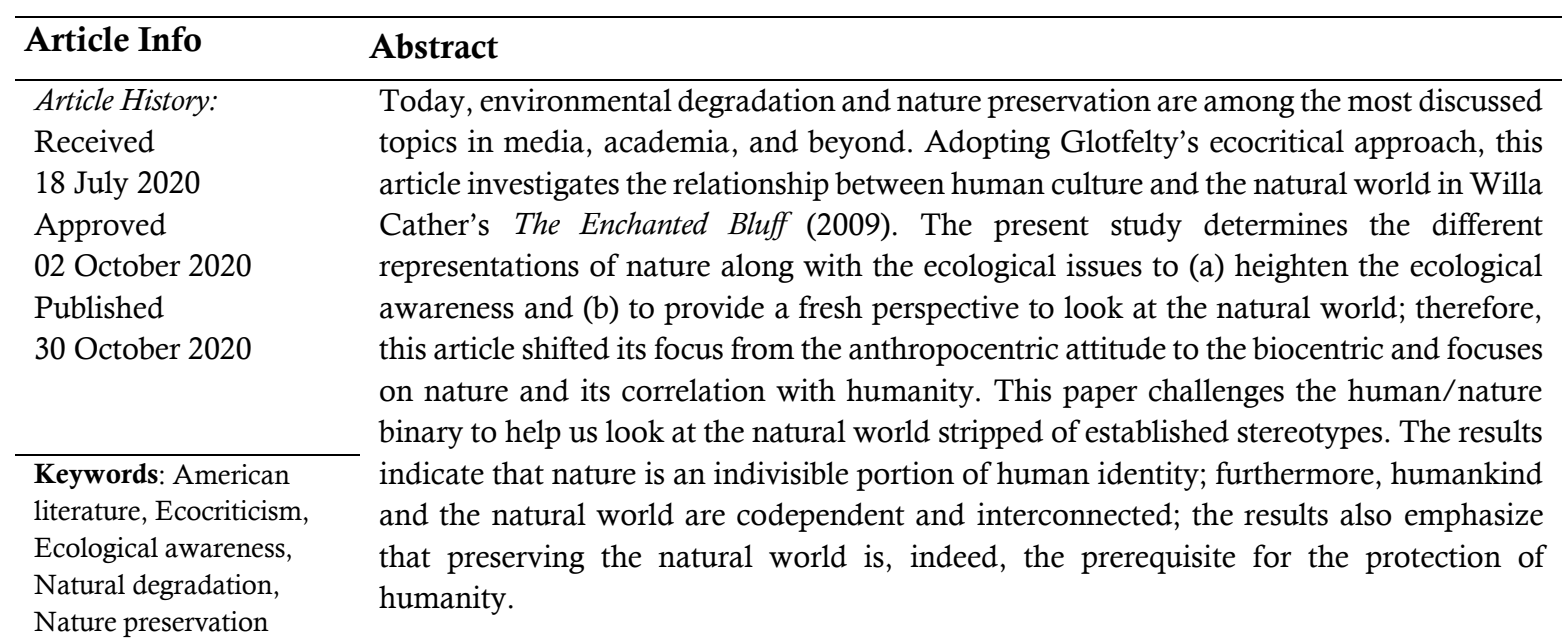

(C) 2020 Universitas Negeri Semarang

$\bowtie$ Corresponding author:
Address: English Department, Payame Noor University, P.O. Box 19395-3697, Tehran, Iran.
E-mail: alireza.sardari@vmail.com

\section{INTRODUCTION}

Humankind's relationship with nature is a reciprocal one, but it is not necessarily equal; that is, despite the enormous pressure that humanity has exerted on nature (such as the increasing production of plastic materials and the release of it in nature), but the natural world has always met human needs without expectations. For example, humankind has always used the natural world _like caves in the distant past_ as a shelter to survive the dangers such as storms, wars, et cetera. With the development of technology, destructive human behaviors like deforestation have accelerated; with that said, humans' relationship with nature is complex, intertwined, and undeniable. And ecocriticism is the response to appreciate this mutual relationship between humanity and nature.

Sometimes the natural world carries out a passive role in stories, meaning that only humans perform an active and dynamic role in the narrative, but this is untrue to Willa Cather's stories; instead, the element of nature is very integral and fundamental, especially in The Enchanted Bluff (2009). An active and dynamic role in the sense that Cather shows a Nature that is alive and independent from human presence. In fact, nature does not need the humans' presence to live, but it is human beings who can live better by respecting nature. Nature in the 
story possesses inconsistent behaviors; the natural world sometimes kindly supports humankind (the bluff as a shelter in the time of war) and sometimes rebels against humans (the storm in the time of peace).

The importance of The Enchanted Bluff is that it tries to adjust the audience's view of the human-nature relationship. In fact, this story offers a new perspective to the reader. And it is the existence of such a fresh view of nature that makes Cather's stories attractive to ecocritics. What she offers in her story about humans' relationship with nature is a novel and important view: Nature is alive, autonomous, and undeniable.

The Enchanted Bluff is in line with the goals and concerns of ecocriticism; and from its analysis, an instructive window opens to the world of nature, so that the reader appreciates the humannature relationship. The importance of this research becomes apparent when we realize that the human-nature relationship requires constant care because, as mentioned before, humanity and nature are interdependent.

Beginning in 1970s, Ecocriticism ${ }^{1}$ has brought with it a new interest in environmental issues and has been able to strengthen its position in interdisciplinary studies. In this regard, many writers devoted their writings to environmental issues known as Eco-fiction. Ecocriticism helps literary and cultural scholars to reread the literary works; this 're-reading' is important in the sense that it gives the reader of the $21^{\text {st }}$ century a new perspective on existence, and the relationship between humanity and the natural world. In fact, for ecocritics "nature really exists, out there beyond ourselves, ... present as an entity which affects us, and which we can affect, perhaps fatally, if we mistreat it" (Barry, 2009, p.243). While anthropocentrism ${ }^{2}$ favors the idea that humankind is the center of the universe, ecocriticism highlights the biocentric attitude rather than anthropocentric. Since the Transcendental movement of the $19^{\text {th }}$ century, North American writers have produced important environmental-conscious works stressing the importance of nature in human life. Focusing on the dichotomy between human (culture) and nature, it is obvious that nature has been on the unprivileged side of the human/nature duality. With the emergence of the Romantic movement in the $19^{\text {th }}$ century, nature was able to regain its forgotten importance; but the unprecedented technological advances of the $20^{\text {th }}$ century along with the unbridled application of warfare in World War I and World War II drastically brought nature to the brink of extinction.

As one of the most prominent American writers of the early twentieth century, Willa Cather's $^{3}$ (1873-1947) ecological consciousness manifests itself in her writing style where various themes such as Nebraska and prairies are prevalent; her attention to the natural world and the ability to depict pastures in great details has attracted ecocritics and other researchers to read her works to this day. "This assumption that nature is both a savior (of body and spirit alike) to be revered, and a subject to be visited paternalistically in the progress of the human sovereign, now seems pervasive" (Watson, 2014, p. 44). What is clear is that humans' endless desires have put pressure on nature; given this fact, the time has come to acknowledge nature and respect its integrity.

The Enchanted Bluff(2009) is the story of six boys: Fritz and Otto Hassler, Percy Pound, Tip Smith, Arthur Adams, and the narrator. They spend a night on an island surrounded by the cornfields near Sand town, Nebraska. Sitting around the campfire, they start talking about general things like places they would like to visit. When it's Tip's turn, he brings up the story of a mysterious red bluff somewhere in New Mexico; boys get very excited and unanimously agree to visit the bluff one day. They promise whoever visits the big red bluff first should recite the story to others. Twenty years pass; nobody has explored it yet. Boys have forgotten the enchanted bluff. Being adults, they successfully failed to fulfill their youth dreams.

Using Glotfelty's (1996) 3-step ecocritical approach, this paper investigates the different representations of the natural world and ecological issues in Willa Cather's TheEnchanted Bluff (2009). As the title of this article speaks for 
itself, this study brings the natural world to the forefront and attempts to give center stage to nature and its relationship with humans. Reflecting upon the human/nature binary, the present study aims to raise the ecological awareness of its reader. Based on Willa Cather's The Enchanted Bluff (2009), this research paper answers the following questions:

How is the natural world represented in Willa Cather's The Enchanted Bluff? And what are the embedded ecological issues in the narrative?

\section{METHODS}

The ecocritical approach principally focuses on the interrelationship between nature and humans. Ecocriticism reconciles literature with the natural world and focuses on the idea that nature genuinely matters because polluting the nature inevitably cause health problems for humans; therefore, human survival depends on the survival of nature; that is why ecocritics are interested in bringing nature to the fore. An ecocritical perspective intentionally brings ecological problems to the forefront to raise peoples' environmental awareness. Emerged out of the ecological awareness of the 1980s, Ecocriticism offers a new perspective on nature and its relationship to human life. As Bertens (2014) states, Ecocriticism "seeks to dismantle . . . the human/nature hierarchy, and sides with posthumanism in its deconstruction of the human/nature dichotomy, an opposition that for ecocritics involves both the human/animal and the culture/nature oppositions" (p. 225).

Ecocriticism's most well-known definition is "the study of the relationship between literature and the physical environment" (Glotfelty, 1996, p. xviii). While Ecocriticism draws from different theories such as deconstruction, feminism, Bakhtinian theories and psychoanalysis, it rejects Formalism that sees a text as an end in itself separated from its context.

All for one Earth; in the past decade, with its boosting scholarship throughout academia and beyond, ecocriticism amplified nature's message of inclusivity: one Earth for all.
Bartosch and Garrard (2014) state "the contribution of ecocriticism is inherently and valuably gradual: making us think anew about the world, nature, and the place of the human animal" (p. 221). The good news is that ecocriticism has been able to create a reliable common ground between people from all walks of life. In the present era, for instance, many celebrities and social influencers speak out their concerns over natural degradation.

Ecocriticism is not a singleton theory; therefore, there is no all-agreed upon set of rules or assumptions; given that fact, this paper adopts Glotfelty's (1996) 3-step ecocritical approach to gain the most reliable results. Cheryl Glotfelty has offered three patterns (stages) for conducting an ecocritical study. The first stage is about 'representations'; that is, "how nature is represented in literature. . . where is the natural world in this text? But nature per se is not the only focus of ecocritical studies of representation. Other topics include the frontier, animals, cities, specific geographical regions, rivers, mountains, deserts, Indians, technology, garbage, and the body" (Glotfelty, 1996, p. xxiii).

In the first stage, an eco-critic investigates the nature's role in the text. To better understand this stage along with other Glatfelty's stages, it is practical to review the questions Anne B. Dobie (2012) suggests: "Does the setting function simply as background, or does it play an active role in the narrative? . . . How is nature affected by human beings in the text? How are the human beings affected by nature? . . . Does the text raise the reader's awareness of the natural world and his or her connections to it?" (p. 243). The second stage spotlights the overlooked nature-oriented writings; this process raises the public's environmental consciousness. And finally, the third stage is concerned with "examining the symbolic construction of species. How has literary discourse defined the human? Such a critique questions the dualisms prevalent in Western thought, dualisms that separate meaning from matter, sever mind from body, divide men from women, and wrench humanity from nature" (Glotfelty, 1996, p. xxiv). As Dobie (2012) 
suggests, the third pattern is about "examining ecocritical issues and questions. ... Are the values expressed in a given literary work consistent with ecological wisdom? How do our metaphors of the land influence the way we treat it?" (p. 245). These questions provide the researcher with a practical outline to follow. The third pattern reveals the overlooked peace and harmony of the natural world.

The present study challenges the human/nature binary; hence, it adopts the first pattern of Glotfelty's ecocritical approach to investigate the different representations of nature along with ecocritical issues in Willa Cather's The Enchanted Bluff (2009).

\section{RESULTS AND DISCUSSION}

\section{Representations of Nature in Willa Cather's The Enchanted Bluff}

\section{Representation of Living Nature}

The story's opening paragraph is an invitation to appreciate nature's presence and autonomy. "while we were cooking our supper the oblique rays of light made a dazzling glare on the white sand about us" (Cather, 2009, p. 1). The natural world is neither silent nor marginalized; nature lives its life, provokes joy and possesses its own voice. Another important instance of nature's joyful life is "the warm layer of air that had rested over the water and our clean sand bar grew fresher and smelled of the rank iron-weed and sunflowers growing on the flatter shore" (Cather, 2009, p. 1). Nature is not there just to be there; nature is there to live and breathe as humans do.

Nature is alive and autonomous. This story is a self-evident instance of deconstructing the human/nature dichotomy. Nature exists in its own realm and has its own rights; its existence is not dependent on human's presence. That is why "Ecophilosophers often criticise the arrogance of anthropocentrism, sometimes using the Ancient Greek term 'hubris' for this fatal flaw of overweening self-righteousness and wilful misuse of power" (Garrard, 2004, p. 179).
Paying close attention to the stream, the narrator states, "We had often noticed a mutinous, complaining note in it at night, quite different from its cheerful daytime chuckle. . . . Our water had always these two moods: the one of sunny complaisance, the other of inconsolable, passionate regret" (Cather, 2009, p. 6). Ecocriticism appreciates nature as a living organism. One noteworthy point here is the river's duality of pleasure/sorrow. Nature is alive and has different sides as humans do: the complaint side and the satisfaction side. To sympathize with stream's joyful note indicates human's understanding as to ignore its complaining note is a misunderstanding.

In the following example, the stream is exhibiting its strength: "Every spring the swollen stream undermined a bluff to the east, or bit out a few acres of cornfield to the west and whirled the soil away to deposit it in spumy mud banks somewhere else" (Cather, 2009, p. 2). 'Change' is an integral part of any living organism; it is one of the most important commonalities between nature and humans. Nature is benign, but it doesn't mean to forget its opposite side. One of the prevalent themes in ecologically oriented works is nature's dark side, where its calmness changes into chaos and its safety into peril.

In the following example, nature displays its harsh face, and the storm acts as an agonizing attacker: The tribe men went "hunting and an awful storm came up ... and when they got back to their rock they found their little staircase had been all broken to pieces . . . While they were camped at the foot of the rock . . a war party from the north came along and massacred 'em to a man" (Cather, 2009, p. 9). When it comes to nature, tranquility and destruction are two sides of the same coin. In fact, the fury of the storm is a reminder not to take nature's tranquility for granted. It is wrong to expect permanent calmness from nature as it is wrong to expect the river's roaring to be incessant. We have to acknowledge that in the world of living organisms having an unchangeable state is not possible. The world is the world of change, not a world of stillness; that is why nature, like humans, has 
different faces. Many "authors, poets, and early scientists, consistently claim that human beings are contiguous with the natural world rather than distinct from it. They collapse the distinction between nature and culture at the same time that they point out similarities between and among all living things" (Nichols, 2011, p. 22).

\section{Representation of Self's Nature}

The human/nature binary has been repeated for so long that we have unknowingly accepted it and unwittingly consider nature not by our side, but against us. "I was already homesick at the thought of quitting the boys with whom I had always played; of leaving the river, and going up into a windy plain ... where there was nothing wilful or unmanageable in the landscape, no new islands, and no chance of unfamiliar birds" (Cather, 2009, p. 3). As the quote speaks for itself, the river is part of the self. As a common ground, the river creates and strengthens friendships. What follows is a selfexplanatory example: "Other boys came and went and used the river for fishing or skating, but we six were sworn to the spirit of the stream, and we were friends mainly because of the river" (Cather, 2009, p. 3). Humans moved away from nature, not vice versa. We are hearing nature, but are we listening to its voice? Nature is not far away; it stands where it is today, where it was yesterday, but will nature survive for tomorrow? Will future generations have the same understanding of nature as we have today?

At 92nd Academy Awards (Oscars 2020), Joaquin Phoenix won the Academy Award for Best Actor; in his acceptance speech, he said:

I think that we've become very disconnected from the natural world. And many of us, what we're guilty of is an egocentric world view: The belief that we're the center of the universe. We go into the natural world and we plunder it for its resources. We feel entitled to artificially inseminate a cow and when she gives birth, we steal her baby, even though her cries of anguish are unmistakable. And then we take her milk that's intended for her calf and we put it in our coffee and our cereal. (Phoenix, 2020, Oscars)
To live peacefully with the natural world, humanity has successfully failed. One of the reasons these problems persist is the way humans understand humanity and the natural world. There is still the attitude that humanity has priority over nature. According to this standpoint, the value of nature is only due to its profitability for humans; that is, nature is only valuable as long as it has benefits for us even at the cost of destroying nature. The persistence of such a worldview has made the state of nature even worse in the present era. Solving nature's problems depends on changing humans' worldviews about their place and nature's place. In other words, the critical state of nature will not change until we have a clear understanding of our relationship with the natural world. As the current situation continues, nature is increasingly marginalized.

The following example spotlights the interdependency between humans and nature. Otto "always dropped out in the spring term as if the river could not get on without him. He and Fritz caught the fat, horned catfish and sold them about the town, and they lived so much in the water that they were as brown and sandy as the river itself" (Cather, 2009, p. 3). The river, in this narrative, lives in the moment. The river departs from its marginalized position that I call Silent (Invisible) Existence into what I call the Audible (Visible) Existence. Silent (Invisible) Existence is when the natural world seems to be silent in the narrative, living as the backdrop only and acting as a stage for humans' unlimited desires. Nature is there just to be there; nothing happens. In this state, nature is on the margins and it is humankind who has placed themselves at the center. Humans want nature not for nature's sake but for their own needs. In this unequal situation, the natural world seems silent because humans do not understand its suffering. And there is a difference between not having a voice and not having an understanding. On the other hand, the Audible (Visible) Existence is when the natural world has a voice for itself and an undeniable presence in the narrative: when the sun shines, the river roars, and the bees dance. In this state, 
nature lives for itself; it has a voice and the ability to bring people together.

In the story Tip "insists that he still means to go down there, but he thinks now he will wait until his boy Bert is old enough to go with him. Bert has been let into the story, and thinks of nothing but the Enchanted Bluff"' (Cather, 2009, p. 13). Tip's emotional bond with the enchanted bluff spotlights the idea that over time dreams remain. For Tip, growing up is not tantamount to abandon his dreams. Nature is a part of his identity; that is why, after twenty years, he still dreams of going to the bluff. Time passes, but dreams remain.

Ignoring nature's harmony reflects the tragic reality that humanity leaves living in the moment. This state of forgetfulness leads to the formation of a vicious circle where we breathe but we do not live; Cather's story puts forward the idea that life is simple, like hearing the sound of morning birds, and getting one's feet wet in the river. To live is to dream and to dream is to live; so it is correct to state that life without dreams is the sickness of humankind.

\section{Representation of Powerful Nature}

Nature is not against humankind. To consider the natural world as a guide, humans must first define their own position in the circle of existence. "Percy . . . "I can see the North Star," he announced, contentedly, pointing toward it with his big toe. "Anyone might get lost and need to know that" (Cather, 2009, p. 5). The story proposes that the key is to look at the natural world as a living organism and to realize that everything in the universe is interconnected. The problem with the system of binary opposition ${ }^{4}$ is that there could only be one privileged side at the expense of destroying the unprivileged side; this system is naturally balanced when only one side wins. By creating this duality, humans always put themselves at the center while nature is marginalized and pushed to the corner; this is where humans underestimate nature's power and forget that nature is there to be the guide, not the enemy. In another example, Otto says "I wonder what would happen to us down here if anything

went wrong with it?" Arthur chuckled. "I wouldn't worry, Ott. Nothing's apt to happen to it in your time. Look at the Milky Way!" (Cather, 2009, p. 5). Arthur's eulogizing-nature eye unveils the duality of faith versus doubt. His perceptive eye reevaluates the assumptions about our surroundings, to look at nature as a place to find solace, not a place to escape from it.

Being mysterious is one of nature's implicit traits; in this regard, many stories have addressed and encouraged these traits. The curiosity of Microcosm (human) to understand the Macrocosm (nature) has produced stories, tales, and narratives about the universe; on the other hand, the relentless efforts of science to crystallize our world has led to experiments about the natural occurrences. Not surprisingly, the confrontation between the two is always a crossroads of new ideas about the universe and its contents. "I wonder where this river really does begin?" Tip mused. That was an old and a favorite mystery which the map did not clearly explain" (Cather, 2009, p. 7). Smitten by the mysterious river, Tip sends the message that we cannot comprehend nature/universe in its entirety. Elsewhere in the story, otto considers stars as the determiner of human destiny: "the stars are all in sort of diagrams," ... . They always look as if they meant something. Some folks say everybody's fortune is all written out in the stars, don't they?" (Cather, 2009, p. 6). This is where nature challenges human's impenetrable independence. In this context, nature not only provides a stage for other actors but also plays an active role itself. The narrator describes the moon as "a galleon in full sail; an enormous, barbaric thing, red as an angry heathen god" (Cather, 2009, p. 6). Also, Percy considers the moon as the determiner of human fate: "When the moon came up red like that, the Aztecs used to sacrifice their prisoners on the temple top" (Cather, 2009, p. 6). And this is the most prominent example of nature's impact on humans as it undermines the humans' unquestioned dominion over nature.

\section{Ecocritical issues}




\section{Relations Between Nature and Culture in The Enchanted Bluff}

There are several dichotomies in this story such as: nature/culture, dream/reality, youth/adulthood, day/night, and past/present. The nature/culture is the most important one. There is still the view that humankind is separate from and superior to nature, and that nature must serve humanity at all costs. Put differently, this view defines humans' relationship with nature as a binary opposition represented as human/nature. Binary opposition as Innes (2010) states is a "relationship of opposition and mutual exclusion between two elements" (p. 74). In this binary, humans consider themselves as the center, while nature is invariably on the margins considered to be the other.

In The Enchanted Bluff, the river deconstructs this binary and reduces the artificial distance established between humanity and nature. Both nature and humanity live in the same bubble where there is no existence outside of it. The river blurs the line between 'I' (self) and 'nature' (other); the river redefines the self, the other, and the relationship between the two. The river highlights the fact that nature is not the other but a part of the self.

Although humans exert pressure on the planet but the natural world has always been a giver. In Cather's narrative, the bluff is the shelter for the tribe; to win wars, they avoided them. "They were a peaceful tribe that made cloth and pottery, and they went up there to get out of the wars. You see, they could pick off any war party that tried to get up their little steps" (Cather, 2009, p. 9). In human's suffering, nature is soothing. In this story, the bluff takes one step forward mediating between humans to form a symbiotic relationship between them. Many natural and human crises have occurred in history, and this is painful. But it is more painful that we humans are accustomed to these crises (Love, 2003, p. 14). In the world of human wars, the peaceful bluff suffers the wounds because the peaceful human in the world of suffering is a bluff. Here is where biocentrism challenges anthropocentrism; in the narrative, the bluff is a loyal shelter to safeguard peace from the humans' ravage, not the stage for them to practice cruelty. The voiceless bluff strives to bridge the gap between humans.

War and food shortage are the most important environmental issues in this story. In fact, war has always been a main reason for the destruction of nature and civilizations throughout history. For instance, the rate of environmental degradation has increased since the first quarter of the twentieth century, that is why "many of the celebrated speculative practices of the post-World War II period have been engaged in or responded to emergent knowledge about the entanglement of biotic and human systems and warnings of environmental decline" (Barber, 2017, p. 349).

Food shortage leads to war, and war leads to food shortage. The bluff suffers from humans' greed and callousness; the following example demonstrates the consequences of war and its irreparable damage to both nature and humanity.

While [the peaceful tribe] were camped at the foot of the rock, ... a war party from the north came along and massacred 'em to a man, with all the old folks and women looking on from the rock. Then the war party went on south and left the village to get down the best way they could. Of course they never got down. They starved to death up there, and when the war party came back on their way north, they could hear the children crying from the edge of the bluff where they had crawled out, but they didn't see a sign of a grown Indian, and nobody has ever been up there since. (Cather, 2009, p. 9)

It is obvious that the tensions of war hurt the body and soul of both nature and humanity. And it is undeniable that the beginning of war is the end of peace, and the end of peace is the beginning of destruction.

\section{CONCLUSION}

Applying Glotfelty's (1996) 3-step ecocritical approach, this paper investigated different representations of nature along with ecological issues in Willa Cather's The Enchanted Bluff (2009). The present study challenged the human/nature binary and principally focused on the relationship between human culture and nature. The results of the research are as follows: The examination of the 'representation of living 
nature' reveals that nature is alive and autonomous; therefore, nature, like humankind, has different moods. The study of the 'representation of self's nature' emphasizes that nature and humanity have an inseparable relationship; besides, nature, with its inherent harmony, deepens friendships between humans. Examining the 'representation of powerful nature' demonstrates that nature is not marginalized. Nature is alive; hence, any reaction from the natural world is possible. The study of the 'relations between nature and culture' indicates that there is a deep correlation between the two in a way that the more humankind insists on culture/nature binary and distancing themselves from nature, the more likely it is to manipulate and destroy the natural world. As humans grow older, they move away from their dreams; as they absorb the human culture, they forget about the natural world; thus, it is correct to state that humanity lives in a bubble of unreconcilable dichotomies like nature/culture, et cetera. And humanity is the product of these binaries. Not surprisingly, human efforts to achieve lasting peace have successfully failed. The results also spotlight the significance of peaceful coexistence of humans with the natural world; since humanity and nature are interdependent, the disappearance of the natural world inevitably leads to the disappearance of human life. If this article can drive only one point home to its reader, it would be to value nature and help its conservation because environmental protection is, indeed, the protection of humanity. Now the question is: Is nature far from us? or we are far from the nature of ourselves?

\section{REFERENCES}

Barber, Daniel A. (2017). Climate, design, and the status of the human: obstacles and opportunities for architectural scholarship in the environmental humanities. In Ursula $\mathrm{K}$. Heise, Jon Christensen, \& Michelle Niemann (Eds.), The Routledge Companion to the Environmental Humanities (pp. 346-357). Routledge.
Barry, Peter. (2009). Beginning Theory: An Introduction to Literary and Cultural Theory. (3rd ed.). Manchester University Press.

Bartosch, Roman, \& Greg Garrard. (2014). The Function of Criticism. A Response to William Major and Andrew McMurry's Editorial. In Roman Bartosch \& Sieglinde Grimm (Eds.), Teaching Environments: Ecocritical Encounters (pp. 220-227). Peter Lang Publishing Group.

Bertens, Johannes W. (2014). Literary Theory: The Basics (3rd ed.). Routledge.

Cather,Willa. (2009). The Enchanted Bluff: Short Story. Pymble, NSW: HarperCollins e-books.

Clark,Timothy. (2011). The Cambridge Introduction to Literature and the Environment. Cambridge University Press.

Dobie, Ann B. (2012). Theory into Practice: An Introduction to Literary Criticism (3rd ed.). Wadsworth Cengage Learning.

Garrard, Greg. (2004). Ecocriticism. Routledge.

Glotfelty, Cheryll, \& Harold Fromm. (1996). The Ecocriticism Reader: Landmarks in Literary Ecology. Georgia University Press.

Innes, Paul. (2010). binary opposition. In Michael Payne \& Jessica Rae Barbera (Eds.), A Dictionary of Cultural and Critical Theory. (2nd ed.). Wiley-Blackwell. (pp. 74-75).

Klages, Mary. (2012). Key Terms in Literary Theory. Continuum International Publishing Group.

Love, Glen A. (2003). Practical Ecocriticism: Literature, Biology, and the Environment. Virginia University Press.

Nichols, Ashton. (2011). Beyond Romantic Ecocriticism: Toward Urbanatural Roosting. Palgrave Macmillan.

Phoenix, Joaquin. (2020, February 10). Best Actor acceptance speech. The 92nd Academy Awards (Oscars), Los Angeles, CA, United States.

Watson, Robert N. (2014). Shadows of the Renaissance. In Greg Garrard (Ed.), The Oxford Handbook of Ecocriticism. Oxford University Press. (pp. 40-59).

\section{NOTES}

1. For more introductory material, see Clark, T. (2011). The Cambridge Introduction to Literature and the Environment, (pp. 1-11).

2. The "assumption that it is only in relation to human beings that anything else has value" (Clark, 2011, p. 2). 
For more information about 'anthropocentrism' and 'anthropocentric', see Park, Chris C. and Michael Allaby. (2013). A Dictionary of Environment and Conservation. Oxford University Press. (page 26).

Also see Rob Boddice (2011). Anthropocentrism: Humans, Animals, Environments. Brill, (pp. 1-18).

3. For more biographical information about Willa Cather, see Woodress, James L. (1989). Willa Cather: A Literary Life. Nebraska University Press, (pp. 3-11). Also see Lee, Hermione. (2017). Willa Cather: Double Lives. (2nd ed.), Vintage Books, a division of Penguin Random House LLC.

4. Binary opposition _also known as binary system_ is an important concept in structuralism. As an unequal inter relationship, this system of thought is designed so that one side of the binary automatically and necessarily dominates the other. Jacques Derrida states, "binary opposition is the fundamental structure of Western philosophy and culture" (Klages, 2012, p. 10). Binary opposition is a situation/state in which two things are considered opposite and placed on either side of the slash; for example, day/night, black/white, et cetera. In this binary, one side of the slash is considered the center while the other side is considered the margin. As an example, in the day/night binary, the 'day' is always considered as the center and original. On the contrary, the 'night' is considered as negative and marginal. 